\title{
GLYCOLIDE/L-LACTIDE COPOLYMER (PGLA) FIBERS FORMED BY WET SPINNING FROM SOLUTION AND MODIFIED WITH CERAMIC NANOADDITIVES
}

\author{
Paulina Król, Grzegorz Szparaga, Teresa Mikołajczyk, Michał Puchalski, Maciej Boguń* \\ Lodz University of Technology, Department of Material and Commodity Sciences and Textile Metrology, \\ Poland, 90-924 Lodz, Zeromskiego 116 Street \\ Correspondence to: Maciej Boguń (E-mail:maciej.bogun@p.lodz.pl)
}

\begin{abstract}
:
The paper presents the results of research into glycolide/L-lactide copolymer (PGLA) fiber formation by wet spinning from solution. The selected process conditions led to fibers with a specific tensile strength of more than $35 \mathrm{cN} / \mathrm{tex}$. Furthermore, ceramic nanoadditives such as hydroxyapatite (HAp) and $\beta$-tricalcium phosphate ( $\beta$-TCP) were used to obtain fibers with osteoconductive properties. It was found that the ceramic nanoadditives reduced the specific strength of fibers (to $24 \mathrm{cN} /$ tex for $\beta$-TCP and to $27 \mathrm{cN} /$ tex for HAp). The paper also presents wide-angle $X$-ray scattering (WAXS) evaluation of the supramolecular structure of the fibers as well as their porosity parameters and microscopic structure. The obtained fibers were woven into a textile fabric with potential applications in biomedical engineering.
\end{abstract}

\section{Keywords:}

PGLA, wet spinning fibers, SEM, WAXS

\section{Introduction}

Progress in orthopedic implantology has given rise to increasingly advanced composite materials designed not only to replace missing biological structures but also to activate the surrounding tissues and accelerate regeneration processes [1-3]. Such materials include polymer-fiber composites, which exhibit anisotropy similar to that of natural tissues and can be used to produce a variety of spatial structures with different orientations of the fiber phase. Owing to their valuable properties enabling a wide range of medical applications, polylactide (PLA) and its copolymers, including poly(lactic-coglycolic acid) (PGLA), may act as both the composite matrix and a filling or strengthening fiber phase [4-6]. The properties of PLA and PGLA depend on the stoichiometric composition of $D$ - and L-lactide repeat units, their distribution along the chain, as well as the molecular weight of the polymer and its polymolecularity [7]. By controlling the process parameters of PLA formation, such as reaction time, temperature, and type of catalyst, one can obtain polymers with desirable characteristics. Indeed, the structure, properties, and molecular weight of PLAs have been discussed in many papers [7-9]. In living organisms, these polymers degrade as a result of ester bond hydrolysis [10-12], which is influenced by both the crystallinity and porosity of the material. Depending on all these factors, the time of total PLA degradation ranges from $12-16$ months to 2-5 years [13-15]. The rate of degradation may also be adjusted by the incorporation of glycolide. Depending on its molecular weight and composition, poly(D,L-lactide-co-glycolide) may be degraded over a period of 1-2 to 5-6 months [15], which enables medical applications, such as suture threads, surgical meshes, and skin implants [16-18]. Owing to the fact that PGLA copolymers also exhibit good cellular adhesion and promote cell proliferation, they are applied in tissue engineering and as the fiber component of biocomposites. PLAand its copolymers are also widely used in research on the regeneration of bone tissue. Ficek et al. in [19] demonstrated the positive results in the treatment of bone cysts using PLA. Timashev et al. [20] analyzed the 3D biodegradable scaffold for bone tissue regeneration. Furthermore, the materials made of the lactic acid copolymers have been used as membranes for the GBR (guide bone regeneration), screws and pins to treat defects in bone [21-23].In proposed solution, the biodegradable polymer constitutes a scaffold for new osteoblasts cell. The polymer will be removed in metabolic processes after execute function and bone regeneration.

Among the various methods ofPLAfiberformation [24-28] (molten polymer extrusion, dry spinning from solution, electrospinning), wet spinning from solution has a number of advantages. Importantly, it eliminates the risk of thermal degradation of the polymer, in contrast to molten polymer extrusion, in which the polymer material must meet strict requirements, including stoichiometric composition and crystalline structure (determining the melting temperature), as well as low moisture content. The problem of thermal degradation during processing of the materials based on copolymers of lactic acid was shown in [29]. However, in the case of forming fibers from wet solution, the problem does not occur, as we confirmed in the intrinsic viscosity of the starting polymer and the fibers obtained [30]. The melt polymer process was occasioned by the increase in molecular mass, which possibly yields the differences in the structure and properties of the materials. On the other hand, wet spinning process is realization in low temperature 
and we did not observe the degradation of PLA.Indeed, the main advantage of wet spinning from solution is that it allows considerable freedom in adjusting the process parameters, which can be configured to impart the desirable properties to the fibers, making them suitable for different applications. Lowtemperature fiber formation facilitates the incorporation (both in the spinning solution and in the fibers) of biomolecules, such as growth factors, protein substances, medicines, or antibacterial agents. The nanoadditives may be homogeneously distributed in the spinning solution by sonication [31].

The use of nanocomposite fibers in biocomposites has contributed to the development of a new generation of materials for bone tissue regeneration [32]. In this area, ceramic nanoadditivesare of great value, and especially calcium phosphates, such as hydroxyapatite (HAp), $\beta$-tricalcium phosphate ( $\beta$-TCP), and bioglasses, which are biocompatible with living tissues. In the literature, there are many reports on the application of such compounds in biomedical engineering [3335]. Importantly, they impart osteoinductive or osteoconductive properties to the implantation materials.In the literature, there are many papers on the use of nanoadditives in bone surgery. In [36], Ma et al. described theosseointegration of polyetheretherketone enriched with nano-hydroxyapatite and calcium silicate. Khoshakhlagh et al. [37] presented research related to bioglass/chitosan composites as bone substitutes. In [38-40], the results of the use of $\mathrm{SiO}_{2}, \mathrm{TiO}_{2}, \mathrm{TCP}$, and silicon nanotubes within the bone tissue are described.

The objective of the present study was to determine the effects of process conditions on the formation of PGLA fibers containing ceramic nanoadditives (HAp or $\beta-\mathrm{TCP}$ ) and to elucidate their influence on the microscopic, supramolecular, and strength properties. In the paper, the fiber formation from lactic acid copolymers according to the method from wet solutionwas developed under the patent [41]. The obtained fibers are to be woven into a fabric strengthening an implantation material stimulating the growth of bone tissue because of the presence of HAp or $\beta-T C P$, which have proven osteoconductive properties.
From the point of view of fiber applications, it is essential to achieve sufficient strength parameters and material porosity to ensure appropriate integration of the material with the natural bone tissue. The process parameters should be configured to obtain fibers with both high strength (more than $20 \mathrm{cN} / \mathrm{tex}$ ) and high porosity, which is contradictory as porosity is known to adversely affect fiber strength.

\section{Experimental}

\section{Polymer characteristics}

PGLA fibers were made with a Resomer LG 824S glycolide/Llactide copolymer, a commercial product of Evonik (Germany). The L-lactide-to-glycolide ratio ranged from 79:21 to $85: 15$ with an intrinsic viscosity of $1.7-2.6 \mathrm{dL} / \mathrm{g}$, according to the manufacturer's specifications. The copolymer purity was suitable for medical applications. The chemical composition of PGLA was verified by means of Fourier-transform infrared (FTIR) spectroscopy using a Nicolet 380 apparatus. Samples were made by casting a PGLA film in methylene chloride. The FTIR spectrum for the Resomer LG 824S PGLA copolymer is given in Figure 1 and shows the following characteristic chemical groups:

- $\quad$ signals corresponding to the vibrations of the $\mathrm{C}-\mathrm{H}$ group (stretching vibrations at $2,995-2881 \mathrm{~cm}^{-1}$ and bending vibrations at $1,454 \mathrm{~cm}^{-1}$ and $1,000-600 \mathrm{~cm}^{-1}$ ),

- two bands attributable to the stretching vibrations of the $\mathrm{C}=\mathrm{O}$ group at 1,758 and $1383 \mathrm{~cm}^{-1}$,

- two bands characteristic of the $\mathrm{CH}_{2}$ group: deformation vibrations at $1,454 \mathrm{~cm}^{-1}$ and twisting vibrations at $868 \mathrm{~cm}^{-1}$,

- two signals of the $\mathrm{CH}_{3}$ group assigned to bending vibrations at 1,454 and $1,364 \mathrm{~cm}^{-1}$,

- a band attributable to the vibrations of the $\mathrm{C}-\mathrm{CH}_{3}$ group at $1,184 \mathrm{~cm}^{-1}$,

- C-O vibrations at $1,184-1,046 \mathrm{~cm}^{-1}$.

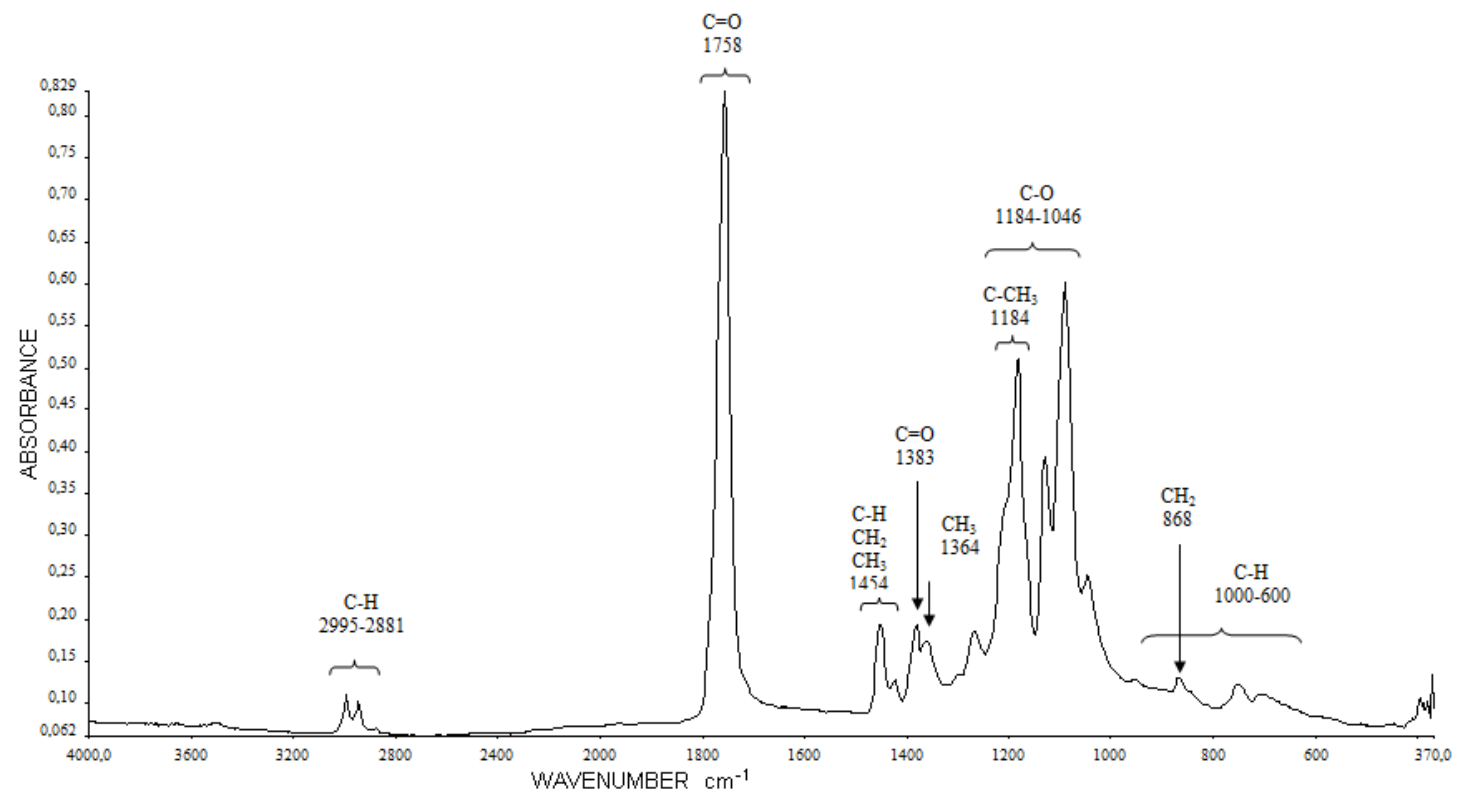

Figure 1. FTIR spectrum of LG 824S 
Molecular analysis of the PGLA copolymer was also conducted by means of gel chromatography (GPC/SEC) with chloroform as the mobile phase (solvent). Measurements were conducted at a column temperature of $35^{\circ} \mathrm{C}$, a solvent flow rate of $0.7 \mathrm{~m} /$ min, and an injection volume of $100 \mu \mathrm{L}$. The concentration was $1.5 \mathrm{mg} / \mathrm{mL}$. Number-average molar mass $\left(M_{n}\right)$, weight-average molar mass $\left(\mathrm{M}_{\mathrm{w}}\right)$, and the degree of polydispersity were determined with the results given in Table 1 (the molecular weight distribution curve is presented in Figure 2). Intrinsic viscosity $(\eta)$ values were determined by means of an Ubbelohde viscometer using methylene chloride as a solvent at $25^{\circ} \mathrm{C}$ and are presented as mean values for six measurements.

The presented molecular weight distribution curve shows typical characteristics preferable for fiber-forming polymers. Its maximum is shifted toward the fraction with a rather high molecular weight. At the same time, the fractions with the lowest and excessively high molecular weights are reduced. Furthermore, the polymolecularity of the polymer $\left(M_{w} / M_{n}=2.6\right)$ is appropriate from the standpoint of fiber formation.

\section{Characterization of nanoadditives}

The properties of nanoadditives introduced to PLAsolutions affect their interactions with both the polymer and the solvent, as well as the mutual interactions in the final fibers. As a result, they may modify the rheological parameters of the spinning solutions, their fiber-forming characteristics, and the resulting fiber properties. Two ceramic nanoadditives were used:

HAp $\left(\mathrm{Ca}_{10} \mathrm{PO}_{4}\right)_{6}(\mathrm{OH})_{2}-\mathrm{a}$ commercial product from SigmaAldrich (synthetic compound no. 677418),
$\beta$-TCP-a commercial product from Sigma-Aldrich (hydrated compound no. 693898).

The nanoadditives were characterized in terms of their size distribution profiles by means of dynamic light scattering (DLS) using a Zetasizer apparatus from Malvern Instruments.

The HAp was found to have a unimodal size distribution with a maximum at $163.9 \mathrm{~nm}$. The size distribution curve for HAp molecules is presented in Figure $3 a$ and an image of HAp is given in Figure $3 a$, showing numerous spherical particles whose sizes are consistent with the DLS results.

$\beta$-Tricalcium phosphate was also characterized by a unimodal size distribution, with a maximum at $202.0 \mathrm{~nm}$. Figure $3 \mathrm{~b}$ gives the molecular size distribution curve for $\beta$-TCP.

Before their addition to spinning solutions, HAp and $\beta$-TCP were suspended in methylene chloride and subjected to sonication to disperse agglomerates using a Sonic 3 cleaner (Polsonic) with a power output of $2 \times 160 \mathrm{~W}$. On the basis of the evaluation of the dispersion effects and suspension stability, it was determined that the dispersion process should be conducted at $5-10^{\circ} \mathrm{C}$ for $15 \mathrm{~min}$ (HAp) and $30 \mathrm{~min}(\beta-\mathrm{TCP})$.

\section{Rheological properties of spinning solutions}

Rheological studies were conducted for a solution of PLA Resomer LG 824S in methylene chloride and analogous solutions containing $5 \% \mathrm{w} / \mathrm{w}$ nanoadditives (HAp or $\beta$-TCP). On the basis of the preliminary research into the rheological properties of PGLA solutions aimed at maintaining apparent

\section{MOLECULAR WEIGHT DISTRIBUTION}

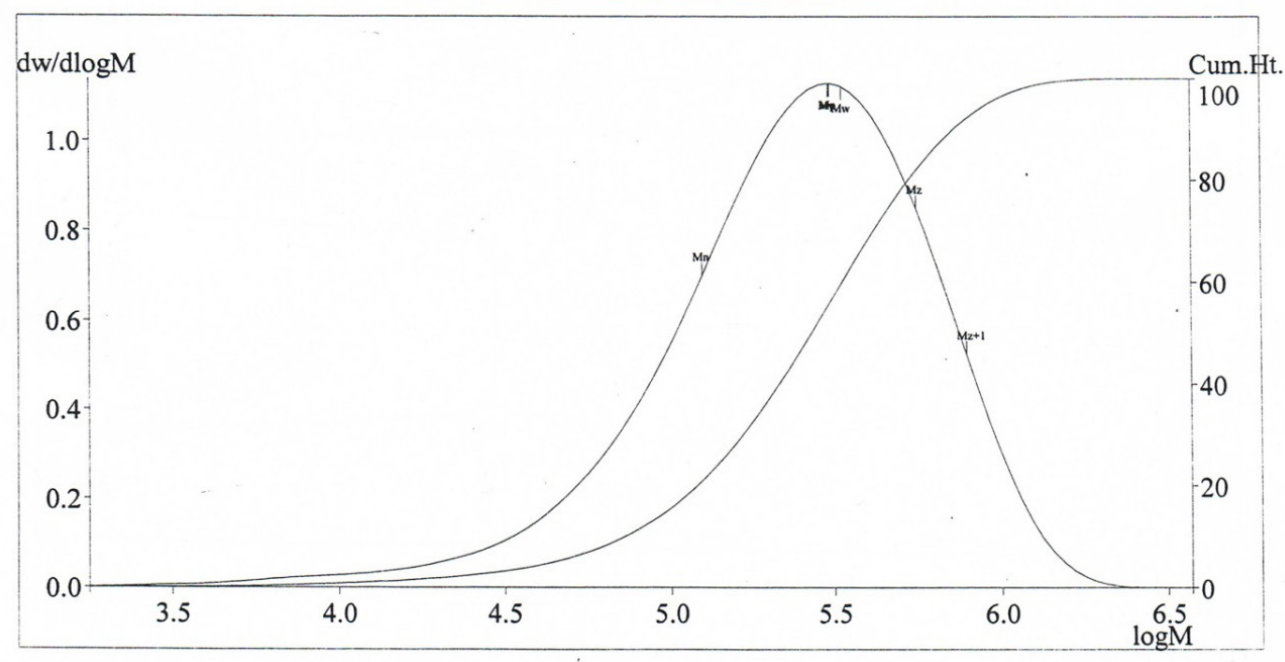

Figure 2. Molecular weight distribution curve for PGLA Resomer 824S

Table 1. Molecular characteristics of PGLA

\begin{tabular}{|c|c|c|c|c|}
\hline Kind of polymer & $\begin{array}{c}\text { Intrinsic viscosity } \\
(\mathbf{d L} / \mathbf{g})\end{array}$ & $\begin{array}{c}\mathbf{M}_{\mathbf{n}} \\
\text { (g/mol; as per PS) }\end{array}$ & $\begin{array}{c}\mathbf{M}_{\mathbf{w}} \\
\text { (g/mol; } \text { as per PS) }\end{array}$ & $\mathbf{M}_{\mathbf{w}} / \mathbf{M}_{\mathbf{n}}$ \\
\hline Resomer LG824S & 1.84 & 128,116 & 334,283 & 2.6 \\
\hline RSD(\%) & 3.26 & 3.2 & 1.1 & 2.2 \\
\hline
\end{tabular}




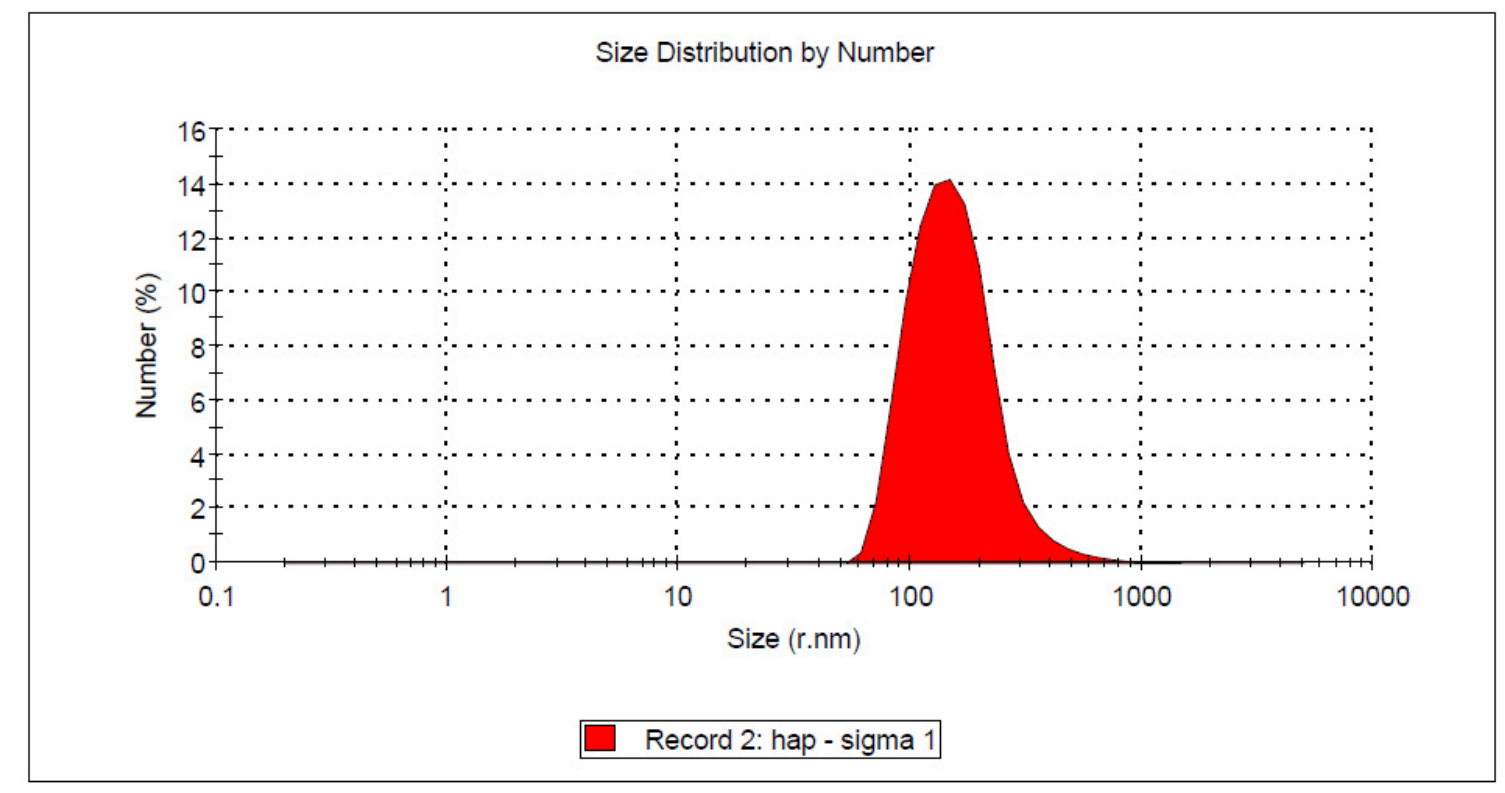

(a)

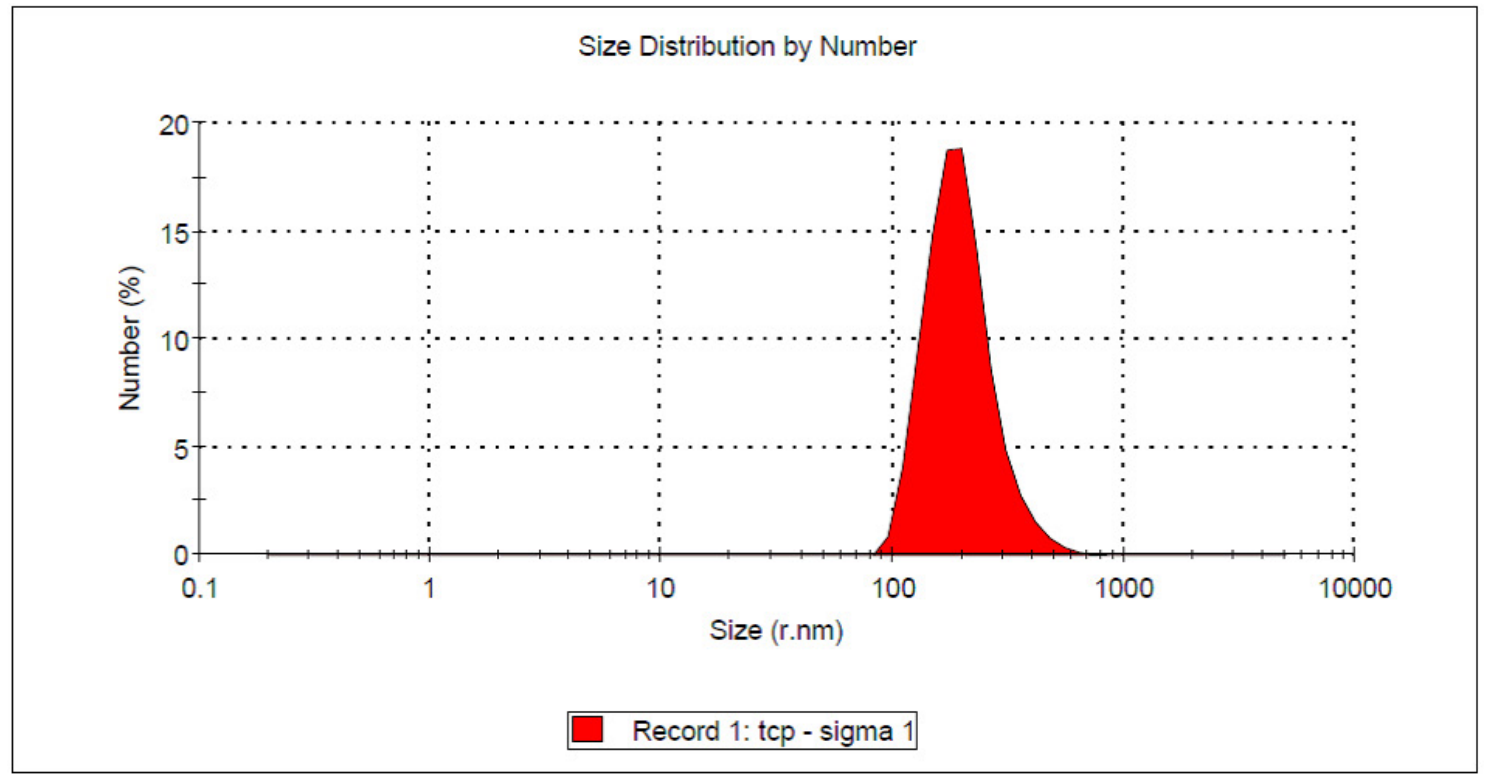

(b)

Figure 3. Size distributions of nanoadditives:(a) hydroxyapatite; (b) $\beta$-tricalcium phosphate

Table 2. Rheological parameters of $18.5 \%$ spinning solutions with and without nanoadditives

\begin{tabular}{|c|c|c|c|}
\hline \multirow{2}{*}{ Kind of nanoadditives } & \multirow{2}{*}{$\begin{array}{c}\text { Concentration of the } \\
\text { nanoadditives(\%) }\end{array}$} & $n$ & $k$ \\
\cline { 3 - 4 } & 5 & 0.968 & 32.75 \\
\hline HAp & 5 & 0.957 & 31.43 \\
\hline TCP & - & 0.963 & 30.41 \\
\hline
\end{tabular}

dynamic viscosity at $30-40 \mathrm{~Pa}$ (suitable for stable fiber formation), the concentration of the examined solutions was $18.5 \%$. The rheological properties of the solutions were studied by means of a Rheolab QC rheometer (Anton Paar) using cylinder $\mathrm{H}$ at $20^{\circ} \mathrm{C}$. The rheological parameters $n$ and $k$ were determined from the Ostwald de Waele equation (Table 2).
Analysis of the obtained plots of shear stress against the shear rate (Figure 4) and the rheological parameters $n$ and $k$ shows that the studied solutions are shear-thinning nonNewtonian liquids $(n<1)$ without a flow limit. The incorporation of nanoadditives led to an increase in $k$, which is a measure of solution consistency, and only small changes in $n$. 


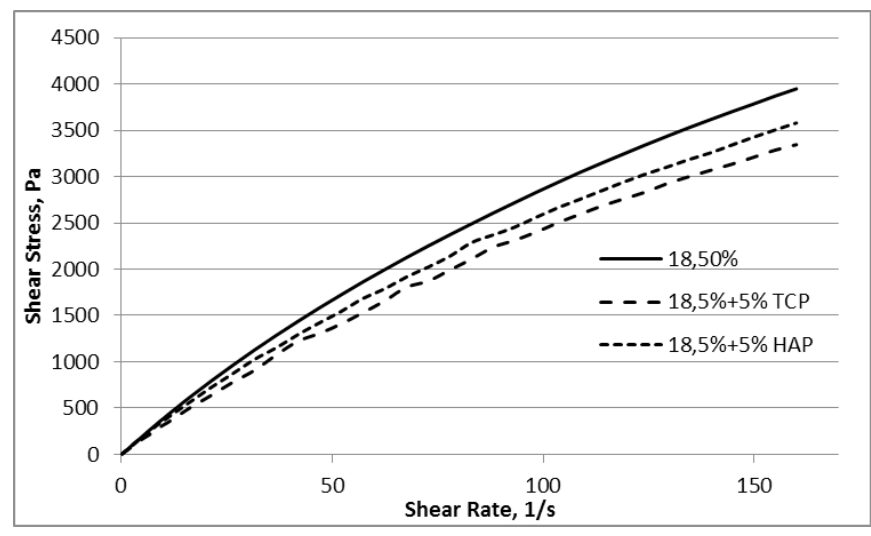

Figure 4. Shear stress as a function of shear rate for PGLA solutions

\section{Fiber formation}

Fibers were formed by wet spinning from $18.5 \%$ solutions of the Resomer LG 824S copolymer in methylene chloride. The applied spinning machine was equipped with exchangeable modules and enabled fiber formation on $1 / 4$ industrial scale. The technological parameters were monitored at all times and maintained on a constant level. The drawing system offered smooth adjustment of linear speed within the range applied. The drawing ratio was monitored by continuous measurement of rotational speed using a digital frequency meter. The spinning solution was fed into the spinneret assembly by means of a gear pump. The spinneret had 500 holes each with a diameter of $0.08 \mathrm{~mm}$. The spinning solution flow rate in the channels was $1 \mathrm{~m} / \mathrm{min}$. The exact parameters of the coagulation process and plasticizing drawing are protected by the Polish patent PL 399819 (2014) [41]. The fibers were drawn in several steps in different media at increasing temperatures with deformations close to the maximum possible values under the process conditions. Subsequently, the fibers were washed and dried under isometric conditions.

\section{Methodology of examining PGLA fiber structure and properties}

Specific tensile strength was determined using an Instron universal testing machine with software ver. IX, pursuant to the standard PN-EN ISO 5079:1999.

Fiber porosity was determined by mercury porosimetry using a Carlo-Erbaporosimeter coupled to a computer system. The porosimeter was used to measure total pore volume, the distribution of pore sizes $3-7,500 \mathrm{~nm}$, and the total internal pore surface area.

The supramolecular structure parameterswere determined by using the wide-angle X-ray scattering (WAXS) method. Measurements were carried out by means of a diffractometerX'Pert PRO from PANalyticalusingCuKa ( $\lambda=$ $0.154 \mathrm{~nm}$ ) as X-ray source and the following tube parameters: accelerating voltage of $40 \mathrm{kV}$ and anode current of $30 \mathrm{~mA}$. $\mathrm{X}$-ray diffraction profiles of powdered samples were taken within the range of angles $2 \theta: 5^{\circ}-45^{\circ}$.
The microscopic structure of the fibers was analyzed using the scanning electron microscopic (SEM) images. A highresolution SEM from FEI Nova NanoSEM 230 equipped with a field emission gun (FEG) was used.

Observations of cell morphologyof Normal Human Osteobalsts,NHOst (Lonza, Switzerland).Adjacent to the materials cells were stained for $1 \mathrm{~min}$ with solution $(1 \mathrm{mg} /$ $\mathrm{mL}$ ) of acridine orange (AO;Sigma, USA), washed with PBSbuffered saline solution (HyClone, Germany), and viewed under microscope. Observations were made using anOlympus CX microscope (Olympus, Japan) with fluorescent attachment. Pictures of adherent cells to the studied materials were made with a digital camera E-520 (Olympus, Japan).

\section{Results and discussion}

\section{Mechanical properties}

The structure and properties of the resulting fibers depend on the structure formed during coagulation and its modification during the subsequent deformation processes. In wet spinning from solution, coagulation is conducted in a solvent-non-solvent mixture whose composition enables two-way mass exchange. The mechanism of these processes (diffusion or "dropletbased"), which determines the porosity of the structure, mostly depends on the composition and temperature of the bath as well as the thickness and compactness of the external layer of the "film" through which diffusion occurs. This is accompanied by phase changes, usually preceded by gelling of the spinning solution stream.

In the coagulation process, the basic parameter determining the structure and properties of the resulting fibers is the asspun draw ratio and the related rate of deformation obtained at the drawing stage. The as-spun draw ratio was changed within a wide range of negative to positive values $(-40 \%$ to $100 \%)$. The tests involved final PGLA fibers (after three-step drawing) containing HAp or $\beta$-TCP nanoadditives, as well as fibers without a nanoadditive. The tensile strength properties of fibers modified with ceramic nanoadditives were compared to those of PGLA fibers without nanoadditives, and their supramolecular and macroscopic structures were examined. The fiber-forming conditions and the strength properties following the three-step drawing process for PGLA fibers are given in Table 3, for fibers containing $\beta$-TCP in Table 4 , and for fibers containing HApin Table 5.

With a view to imparting high strength properties to PGLA fibers, the drawing process was conducted in three steps in media with increasing temperatures. The highest specific tensile strength (34.6 cN/tex, see Table 3) was found for fibers formed with a negative as-spun draw ratio $(-20 \%)$. Their elongation at break was $11-22 \%$, which makes the fibers suitable for textile products. It should be noted that in all cases, these parameters were achieved because of a high total draw ratio, which ranged from $431 \%$ to $696 \%$, depending on the as-spun draw ratio (Table 3 ). In turn, in a two-step drawing process, the maximum total draw ratio was $320-350 \%$. The incorporation 
Table 3. Fiber-forming conditions and tensile strength properties for PGLA fibers without nanoadditives

\begin{tabular}{|c|c|c|c|c|c|c|}
\hline $\begin{array}{c}\text { Sample } \\
\text { symbol }\end{array}$ & $\begin{array}{c}\text { As-spun draw } \\
\text { ratio } \\
(\%)\end{array}$ & $\begin{array}{c}\text { Total draw } \\
\text { ratio } \\
(\%)\end{array}$ & $\begin{array}{c}\text { Linear mass } \\
\text { (tex) }\end{array}$ & $\begin{array}{c}\text { Tenacity } \\
\text { (cN/tex) }\end{array}$ & $\begin{array}{c}\text { Elongation at } \\
\text { brake } \\
(\%)\end{array}$ & $\begin{array}{c}\text { Tensile } \\
\text { strength (MPa) }\end{array}$ \\
\hline LG1W & -50 & 696 & 220 & $27.28 \pm 2.71$ & $22.26 \pm 1.45$ & $216.38 \pm 40.04$ \\
\hline LG2W & -20 & 581 & 120 & $34.62 \pm 3.26$ & $21.99 \pm 0.78$ & $274.97 \pm 95.18$ \\
\hline LG3W & +20 & 533 & 100 & $28.88 \pm 2.15$ & $20.96 \pm 3.62$ & $243.57 \pm 36.50$ \\
\hline LG4W & +50 & 524 & 60 & $31.30 \pm 1.95$ & $15.36 \pm 0.69$ & $185.52 \pm 35.70$ \\
\hline LG5W & +100 & 431 & 80 & $17.56 \pm 0.99$ & $11.68 \pm 0.76$ & $165.02 \pm 13.41$ \\
\hline LG6W & -40 & 614 & 160 & $32.82 \pm 0.89$ & $22.04 \pm 0.42$ & $222.17 \pm 44.89$ \\
\hline
\end{tabular}

Table 4. Fiber-forming conditions and tensile strength properties for PGLA fibers containing $\beta$-TCP

\begin{tabular}{|c|c|c|c|c|c|c|}
\hline $\begin{array}{c}\text { Sample } \\
\text { symbol }\end{array}$ & $\begin{array}{c}\text { As-spun draw } \\
\text { ratio } \\
\text { (\%) }\end{array}$ & $\begin{array}{c}\text { Total draw } \\
\text { ratio } \\
\text { (\%) }\end{array}$ & $\begin{array}{c}\text { Linear mass } \\
\text { (tex) }\end{array}$ & $\begin{array}{c}\text { Tenacity } \\
\text { (cN/tex) }\end{array}$ & $\begin{array}{c}\text { Elongation at } \\
\text { brake } \\
\text { (\%) }\end{array}$ & $\begin{array}{c}\text { Tensile } \\
\text { strength (MPa) }\end{array}$ \\
\hline LGT1W & -40 & 620 & 166 & $27.00 \pm 2.37$ & $17.93 \pm 0.75$ & $193.93 \pm 40.96$ \\
\hline LGT2W & -20 & 533 & 144 & $27.95 \pm 2.01$ & $18.12 \pm 0.92$ & $216.55 \pm 38.47$ \\
\hline LGT3W & +20 & 464 & 101 & $20.43 \pm 3.55$ & $14.38 \pm 4.13$ & $124.48 \pm 16.51$ \\
\hline LGT4W & +50 & 426 & 92 & $19.44 \pm 0.89$ & $10.75 \pm 0.92$ & $139.79 \pm 30.10$ \\
\hline
\end{tabular}

Table 5. Fiber-forming conditions and tensile strength properties for PGLA fibers containing HAp following three-step drawing.

\begin{tabular}{|c|c|c|c|c|c|c|}
\hline $\begin{array}{c}\text { Sample } \\
\text { symbol }\end{array}$ & $\begin{array}{c}\text { As-spun draw } \\
\text { ratio } \\
\text { (\%) }\end{array}$ & $\begin{array}{c}\text { Total draw } \\
\text { ratio } \\
\text { (\%) }\end{array}$ & $\begin{array}{c}\text { Linear mass } \\
\text { (tex) }\end{array}$ & $\begin{array}{c}\text { Tenacity } \\
\text { (cN/tex) }\end{array}$ & $\begin{array}{c}\text { Elongation at } \\
\text { brake } \\
\text { (\%) }\end{array}$ & $\begin{array}{c}\text { Tensile } \\
\text { strength (MPa) }\end{array}$ \\
\hline LGH1W & -20 & 543 & 153 & $20.16 \pm 1.69$ & $16.07 \pm 2.61$ & $146.80 \pm 31.77$ \\
\hline LGH2W & +20 & 477 & 90 & $24.29 \pm 2.16$ & $14.87 \pm 1.07$ & $147.15 \pm 40.14$ \\
\hline LGH3W & +50 & 374 & 95 & $14.76 \pm 0.89$ & $11.70 \pm 1.45$ & $115.18 \pm 27.64$ \\
\hline LGH4W & +100 & 373 & 80 & $5.65 \pm 0.44$ & $2.89 \pm 0.41$ & $41.29 \pm 10.91$ \\
\hline
\end{tabular}

of the nanoadditives $\beta$-TCP or HAp in PGLA resulted in lower strength of the fibers. Fibers modified with $\beta$-TCP exhibited a maximum specific tensile strength of $27.9 \mathrm{cN} / \mathrm{tex}$, while the corresponding value for fibers with HAp was $24.3 \mathrm{cN} / \mathrm{tex}$. These results were obtained at as-spun draw ratios of $-20 \%$ and $+20 \%$, respectively (Tables 4 and 5 ). Importantly, the addition of $\beta$-TCP to the polymer caused a shift in the optimum as-spun draw ratio toward higher values (in order to ensure maximum specific strength). A similar pattern was previously observed for zinc alginate [42], and it is probably attributable to different degrees of interactions between the nanoadditive and the polymer. At more positive as-spun draw ratios, the studied fibers show a general tendency toward lower tensile strength and the maximum total draw ratio also decreases because the structures produced at the stage of coagulation and their susceptibility to further deformation are mostly influenced by the longitudinal velocity gradient, changing along the fiber formation path. The value of that gradient is dependent on the as-spun draw ratio, and its effect is the orientation of structural elements along the fiber axis. The higher the as-spun draw ratio, the lesserthe obtained structure will be susceptible to further deformation (lower Rc). At the same time, the longitudinal velocity gradient increases due to the higher values of the asspun draw ratio. This enables a better and denser arrangement of the structural elements. However, such structures are less susceptible to deformation processes at the stage of drawing. This is consistent with the general regularities concerning the formation of fibers by wet spinning from solution [43].That is why the strength of the studied fibers decreases with higher values of the as-spundraw ratio. These processes are also affected by the presence of nanoadditives in the coagulating polymer stream. The decreased strength of PGLA fibers 
modified with nanoadditives may be explained by the higher internal friction of the system subjected to deformation. The strength properties of the fibers are associated not only with the orientation of structural elements along the fiber axis but also with their crystalline structure (degree of crystallinity and crystallite size).

\section{Supramolecular structure}

In Figure 5, X-ray diffractograms obtained for studied fibers are presented. In the WAXS profiles of samples, one dominant diffraction peak located at $2 \theta 16.5^{\circ}$ corresponding to (110)/ (200) $\alpha$ or $\alpha^{\prime}$ forms of PLA is clearly visible. The absence of crystalline peak from PGLA confirms thelack of co-crystallizing of glycolate and lactate, and the fact that low concentration of the component in the copolymers remains largely amorphous. The presented $\mathrm{X}$-ray diffractogramsalso contain diffraction peaks above $2 \theta 25^{\circ}$ corresponding to crystalline structure of HAp and TCP.

The structural analysis of the investigated samples was obtained by the deconvolution of the patterns into the amorphous halo and the crystalline peaks (Figure 5). For this analysis, the experimental data were fitted by a combination of the Gauss and Lorentz functions calculated using the WAXSFIT software $[44,45]$ based on Hindeleh and Johnson's method. The shapes of the amorphous halo and the mesomorphic and crystalline peaks were selected according to the model proposed by Stoclet et al. [46].

The crystalline and mesomorphic phase contents in the studied materials were calculated according to the following equation:

$$
\chi_{C}=\frac{A_{C}}{A_{C}+A_{A}},
$$

where $A_{A}$ and $A_{C}$ are the integral intensities of the amorphous halo and the peaks originating from the crystalline or mesomorphic phase, respectively.

Another characteristic feature of the structure formed under different conditions was detected by analyzing the lattice length (d-spacing) calculated according to Bragg's equation:

$$
d=\frac{\lambda}{2 \sin \theta},
$$

where $\lambda$ is the wavelength of the $X$-ray source $(0.15418 \mathrm{~nm})$ and $\theta$ is the angle of the reflection (half of $2 \theta$ of peak position).

The last factor studied by the WAXS method is the crystalline size corresponding to (hkl) planes direction. This factor was determined from diffraction peak widths using Scherrer's formula:

$$
\boldsymbol{L}_{(\boldsymbol{h} k l)}=\frac{\boldsymbol{K} \boldsymbol{\lambda}}{\boldsymbol{B} \cos \boldsymbol{\theta}}
$$

where $L_{(h k l)}$ is theaverage size of crystalline areas perpendicular to lattice planes (hkl), $\theta$ is the Bragg angle for planes (hkl), $\lambda$ is the wavelength of $X$-ray radiation (for CuKa $\lambda=0.154 \mathrm{~nm}$ ), $B$ is the half width of the diffraction peak for planes (hkl), $K$ is theScherrer constant for the particular polymer $(0.9$ in this case).

The precise structural analysis conducted by the use of numerical method shows the differences between samples(Table 6). The dominate structure of the studied materials is the mesophase. The domination of preordered crystalline form results from the low overall crystallinity of the studied samples. The thermal and drawing regime during wet spinning process is probably less favorable for PLA crystallization than melt spinning process

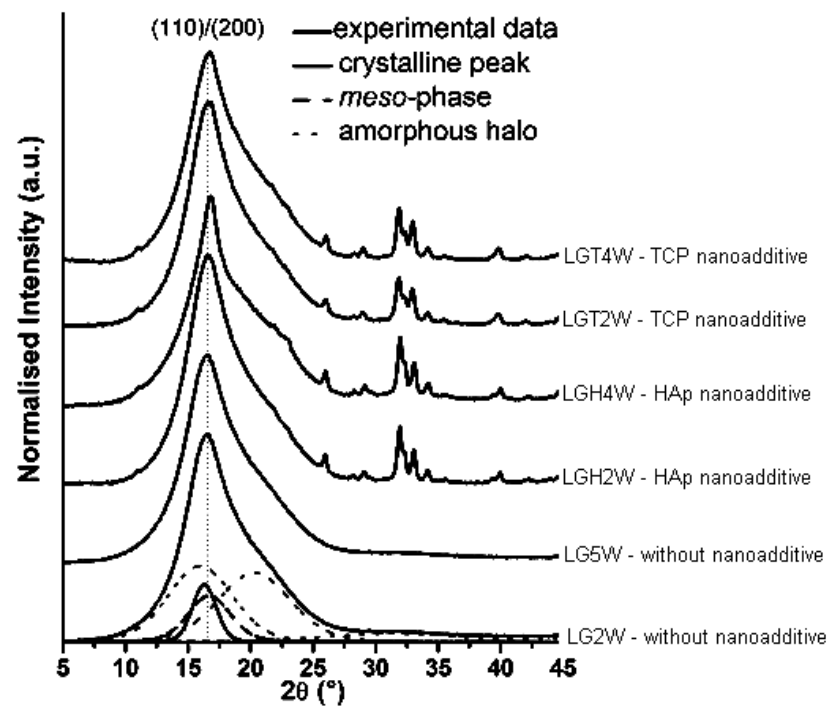

Figure 5. WAXS diffractogram of PGLA fibers showing crystalline

\begin{tabular}{|c|c|c|c|c|c|c|}
\hline $\begin{array}{l}\text { Sample } \\
\text { symbol }\end{array}$ & $\begin{array}{c}\text { Kind of } \\
\text { nanoadditives }\end{array}$ & $\begin{array}{c}\text { Contain of } \\
\text { crystalline } \\
\text { phase } \\
(\%)\end{array}$ & $\begin{array}{c}\text { Contain of } \\
\text { mesophase } \\
(\%)\end{array}$ & $\begin{array}{c}\text { Overall } \\
\text { crystallinity } \\
(\%)\end{array}$ & $\begin{array}{c}\mathrm{L}_{(110) /(020)} \\
(\mathrm{nm})\end{array}$ & $\begin{array}{c}d_{(110) /(020)} \\
(\mathrm{nm})\end{array}$ \\
\hline LG2W & - & 9.2 & 13.5 & 22.8 & 5.43 & 0.543 \\
\hline LGT2W & $\beta$-TCP & 4.4 & 12.3 & 16.7 & 5.70 & 0.539 \\
\hline LGT4W & $\beta$-TCP & 3.8 & 12.5 & 16.3 & 6.85 & 0.533 \\
\hline LGH2W & HAp & 5.8 & 13.3 & 19.1 & 5.40 & 0.540 \\
\hline LGH4W & HAp & 4.9 & 6.2 & 11.1 & 7.31 & 0.528 \\
\hline
\end{tabular}
peaks and amorphous components.

Table 6. Supramolecular structure of PGLA fibers without nanoadditives and PGLA fibers containing $\beta$-TCP or HAp. 
of forming the fibrous materials $[47,48]$. The PGA component in the copolymer could also be not without significance in the case of crystallization of PLA chains.

The obtained resultsalso present the influence of nanoadditives on the crystallization of studied fibers. The addition ofHAp and TCP decreases the content of the crystalline phase and the overall crystallinity what affects the physical properties of studied materials, for example, mechanical properties.The reduction of the degree of crystallinity in the case of fibers containing nanoadditives is most likely due to the more difficult orientation of the macromolecules during the stretching process as a result of an increase in the internal friction of the system. Nanoadditives create a kind of obstacle to macromolecules during their orientation along the road of formation.

What is worth noting, the most visible influence on the physical properties has the structure of the crystalline phase. The fibers characterized by optimal and expected physical properties are obtained only in the case when the d-spacing and the crystalline size are around 0.54 and $5.5 \mathrm{~nm}$, respectively. The physical properties changedwhen the d-spacing is around 0.53 $\mathrm{nm}$ despite the fact that the crystals of PLA are increasing.

The observed phenomenon confirms the strong impact of $\mathrm{d}$-spacing on the physical properties of fibers, what was reported previously. The change in wet spinning parameters causes the disorder-to-order phase transition (á to $\alpha$ form) of poly(L-lactide) [49]. The domination of orthorhombic ordered $\alpha$ form results in less strain of fibers than those in the case of pseudo-orthorhombic á form.

\section{Porosity and microscope analysis}

The total pore volume determined by mercury porosimetry was $0.3-0.4 \mathrm{~cm}^{3} / \mathrm{g}$, with a pore surface area of $18.25-24.5 \mathrm{~m}^{2} / \mathrm{g}$. The volume of $3-1,000 \mathrm{~nm}$ pores ranged from 0.068 to $0.076 \mathrm{~cm}^{3} / \mathrm{g}$, which corresponds to a percentage share of $18.2-21.32 \%$. Wherein, the average pore size range was $75-300 \mathrm{~nm}$. Pores of such sizes are responsible for the absorption of moisture by capillary condensation, which implies very low moisture sorption $(0.8-1.0 \% \mathrm{RH})$. Pores of approximately $7,500 \mathrm{~nm}$ entail the presence of voids between elementary fibers, which may be considered favorable because it may facilitate the access of bodily fluids to the surface of elementary fibers in the bundle, thus making it easier for the fibers to be resorbed in the human organism. The obtained type of porosity may be termed a compact, fine pore structure, which is corroborated by SEM images of crosssections of the studied fibers (Figure 6). The images also show the presence of nanoadditives dispersed in the fibers. The fiber surface (Figure 7) exhibits numerous cracks of different lengths and depths, which is typical of fibers formed by wet spinning from solution. This surface inhomogeneity is beneficial because of the important role played by thePGLA fibers isin the composite material (the presence of rough areas improves the adhesion of bone cells following implantation). The beneficial effect of porosity for better adhesion of cells to the fibers has been found in one of our recent unpublished work on the different types of fibers (calcium alginate, chitin derivatives, carbon fibers).

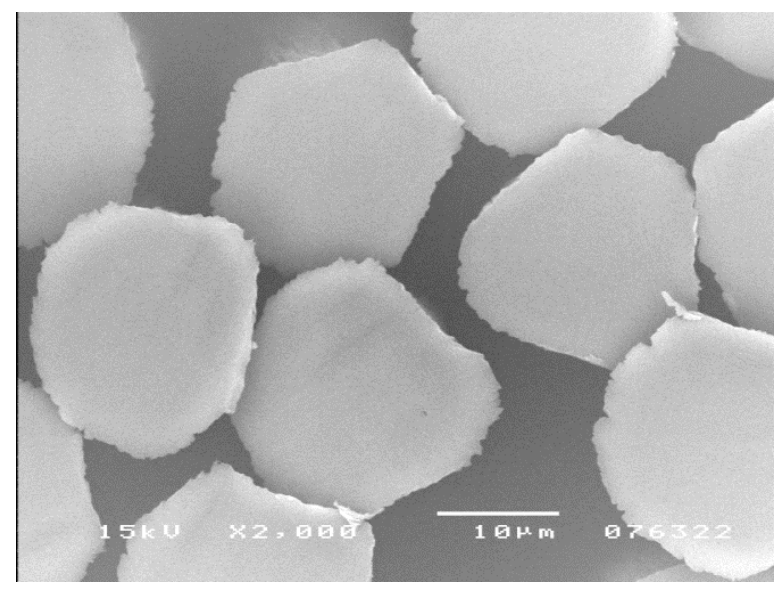

(a)

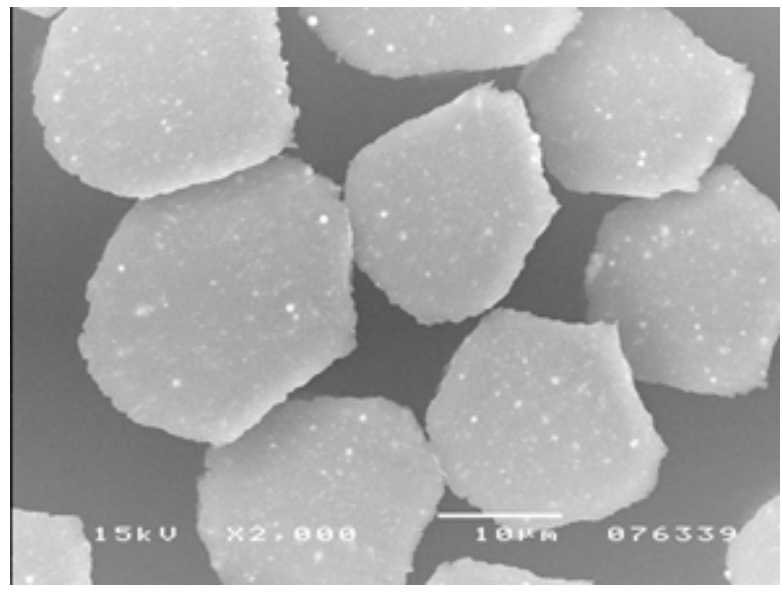

(b)

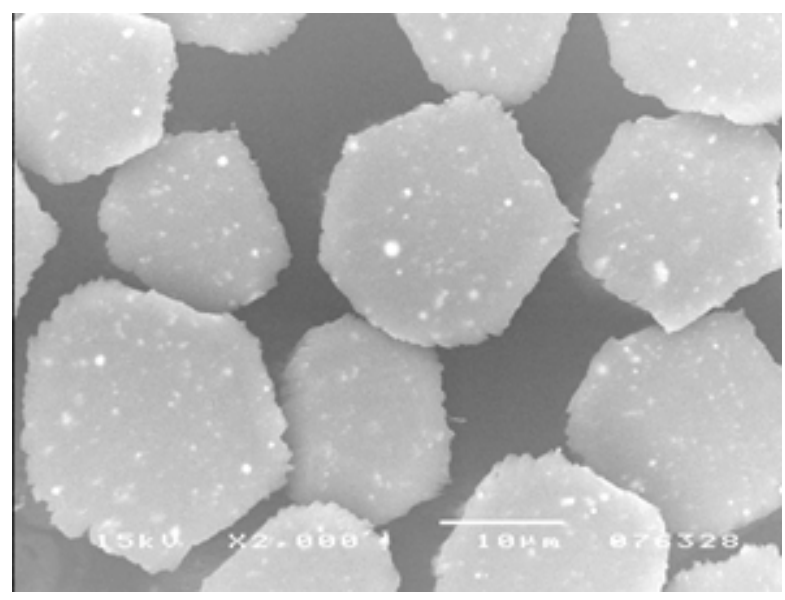

(c)

Figure 6. SEM images of cross section of PGLA fibers: (a) LG2W sample without nanoadditives; (c) LGT2W sample with $\beta$-TCP nanoadditives; and(c) LGH2W sample with HApnanoadditives

\section{Applications of PGLA nanocomposite fibers}

PGLA fibers modified with $\beta$-TCP, with a specific tensile strength of $28 \mathrm{cN} /$ tex and with 500 elementary fibers per bundle, were used to produce a plain-weave fabric using a laboratory loom. The resulting fabric had a surface density of $458 \mathrm{~g} / \mathrm{m}^{2}$. Subsequently, the fabric was subjected to in vitro studies, which will be reported in a separate publication. It should be noted that the studied implantation material makes it possible to obtain structures with predetermined directional proliferation of cells (osteoblasts), as shown in Figure 8. 


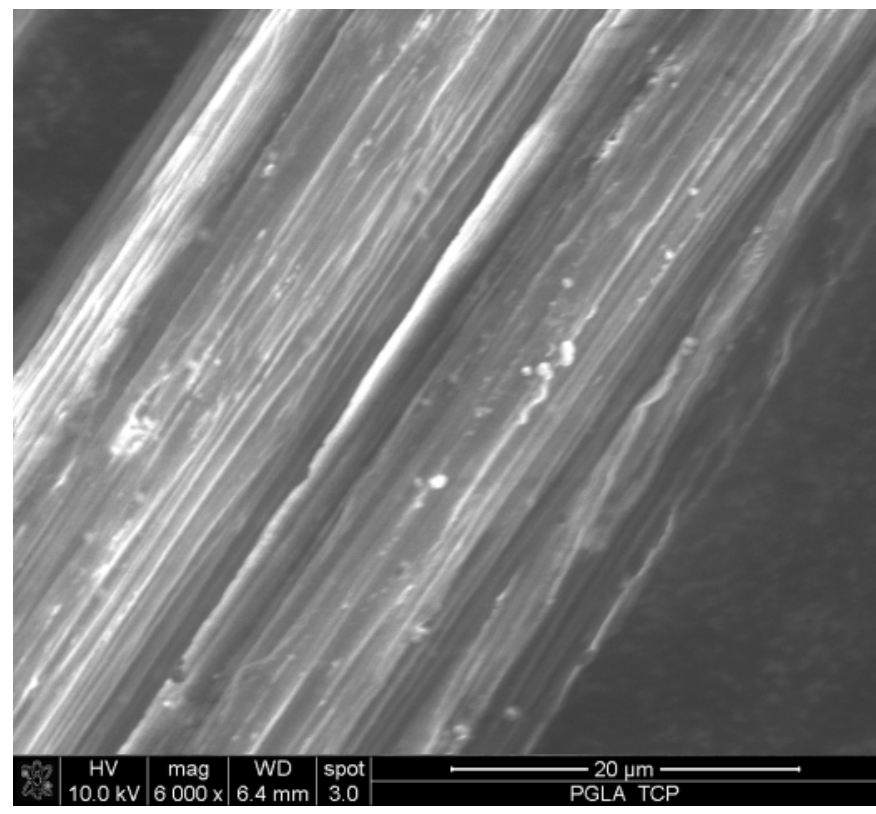

Figure 7. SEM image of PGLA fibers containing $\beta$-TCP nanoadditives(LGT2W sample)
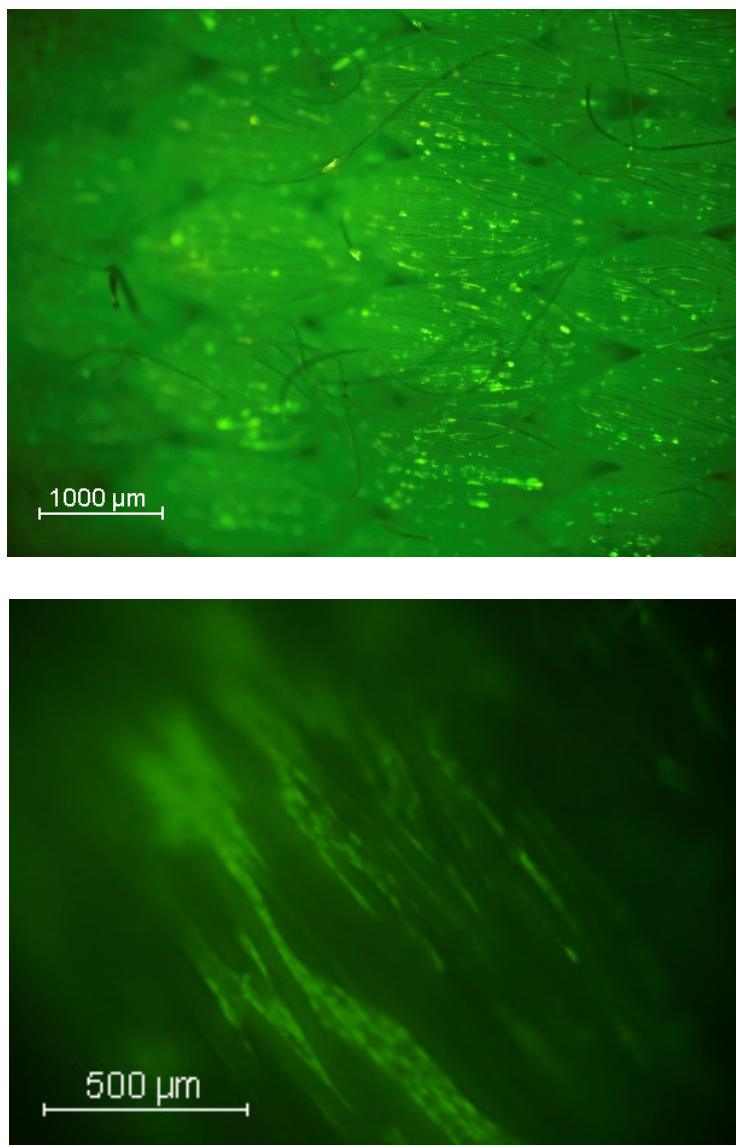

Figure 8. Fluorescence microscopic image of cell morphology after 7 days on a fabric made of PGLA fibers containing $\beta$-TCP nanoadditives.

\section{CONCLUSIONS}

The presented study investigated the formation conditions of PGLA fibers with a view to obtaining high tensile strength properties. The determined as-spun draw ratio values at which the fibers met the strength criteria were $-20 \%$ for PGLA fibers without nanoadditives and containing $\beta-T C P$ and $+20 \%$ for PGLA fibers containing HAp. The specific tensile strength of
PGLA fibers modified with $\beta$-TCP and HAp is 27.9 and $24.3 \mathrm{cN} /$ tex, respectively. Moreover, the macroscopic structure of the fibers is suitable for their purpose and their total pore volume ranges from 0.3 to $0.4 \mathrm{~cm}^{3} / \mathrm{g}$.

The supramolecular structure of the fibers corresponds to their tensile strength properties, which are in turn affected by the deformation processes occurring during fiber formation. At the stage of coagulation, these processes are mostly affected by the longitudinal velocity gradient (dependent on the as-spun draw ratio), and at the stage of stepwise drawing, they are influenced by the maximum total draw ratio.

The suitability of nanoadditive-modified PGLA fibers with the structure and properties described earlier for the production of biocomposites for bone tissue regeneration has been confirmed by in vitro studies.

\section{ACKNOWLEDGMENTS}

The research presented in the article was partially financed by The National Science Centre of Poland, project No. N N508 487638 and 14-148-1-2117, statuary activity by the Lodz University of Technology, Department of Material and Commodity Sciences and Textile Metrology, Poland

\section{REFERENCES}

[1] Sharma V,Mobin SM. Cytocompatible peroxidase mimic CuO:graphenenanosphere composite as colorimetric dual sensor for hydrogen peroxide and cholesterol with its logic gate implementation. Sensors and Actuators, B: Chemical 2017; 240:338-348.

[2] Davachi S.M.,ShiroudHeidari B,Hejazi I,Seyfi J,Oliaei E.,Farzaneh A, Rashedi H.Interface modified polylactic acid/ starch/poly $\varepsilon$-caprolactone antibacterial nanocomposite blends for medical applications. Carbohydrate Polymers 2017; 155:336-344

[3] Mahmoudi N, Simchi A. On the biological performance of graphene oxide-modified chitosan/polyvinyl pyrrolidonenanocomposite membranes: In vitro and in vivo effects of graphene oxide.Materials Science and Engineering C 2017; 70:121-131.

[4] Ray SS, Okamoto M. Polymer/layered silicate nanocomposites: a review from preparation to processing, Prog. Polym. Sci. 2003; 28:1539-1641.

[5] Xue Jiang, Yan Luo, XiuzhiTian, Dan Huang, Narendra Reddy, and Yiqi Yang; Chemical Structure of Poly(lactic acid) w: Poly(lactic acid): Synthesis, Structures, Properties, Processing, and Applications; edited by: Auras R., Lim L.T., Selke S.E.M., Tsuji H.; John Willey \& Sons 2010.

[6] Perepelkin KE. PolylactideFibres: Fabrication, Properties, Use, Prospects. A Review. Fibre Chemistry 2002; 34(2):85100.

[7] Auras R, Haste B, Selka S. An overview of polylactides as packaging materials. Macromolecular Bioscience 2004; 4:835-864.

[8] Duda A, Penczek S. Polilaktyd [poli(kwasmlekowy)]: synteza, właściwości i zastosowania. Polimery 2003;48(1):16-23. 
[9] Hyon SH, Jamshidi K, Ikada Y. Synthesis of polylactides with different molecular weights. Biomaterials 1997; 18(22):1503-8.

[10] Bellini $D$, Cencetti C, Sacchetta AC,Battista AM,Martinelli A.,Mazzucco L, Scotto D'Abusco A,Matricardi P. PLAgrafting of collagen chains leading to a biomaterial with mechanical performances useful in tendon regeneration. Journal of the Mechanical Behavior of Biomedical Materials 2016; 64:151-160.

[11] Rodriguez EJ,Marcos B,Huneault MA.Hydrolysis of polylactide in aqueous media.Journal of Applied Polymer Science 2016; 133(44): Article number 44152

[12] Bobel AC,Lohfeld S, Shirazi RN,McHugh PE. Experimental mechanical testing of Poly (L-Lactide) (PLLA) to facilitate pre-degradation characteristics for application in cardiovascular stenting. Polymer Testing 2016; 54:150158.

[13] Chlopek J.,Morawska-Chochol A,Paluszkiewicz C, Jaworska J,Kasperczyk J,Dobrzyński P. FTIR and NMR study of poly(lactide-co-glycolide) and hydroxyapatite implant degradation under in vivo conditions.Polymer Degradation and Stability 2009; 94(9):1479-1485.

[14] Mitchell MK, Hirt DE.Degradation of PLA fibers at elevated temperature and humidity.Polymer Engineering and Science 2015; 55(7):1652-1660.

[15] Liu JW, Zhao Q, Wan CX.Research progresses on degradation mechanism in vivo and medical applications of polylactic acid.Space medicine \& medical engineering 2001; 14(4):308-312.

[16] Heidari BS,Oliaei E,Shayesteh H,Davachi SM,Hejazi I,Seyfi J,Bahrami M,Rashedi H.Simulation of mechanical behavior and optimization of simulated injection molding process for PLA based antibacterial composite and nanocomposite bone screws using central composite design.Journal of the Mechanical Behavior of Biomedical Materials 2017; 65:160-176.

[17] Krucińska I, Chrzanowska O, Boguń M, Kowalczuk M, Dobrzyński P. Fabrication of PLGA/Hap and PLGA/PHB/ Hap Fibrous Nanocomposite Materials for Osseous Tissue Regeneration. Autex Research Journal 2014; 14(2):95-110

[18] Ghosh S, Vasanthan N. Structure development of poly (Llactic acid) fibers processed at various spinning conditions. Journal of Applied Polymer Science 2006; 101(2):1210 1216.

[19] Ficek K, Filipek J, Wojciechowski P, Kopec K, StodolakZych E, Blazewicz S. A bioresorbablepolylactide implant used in bone cyst filling. Journal of Materials Science: Materials in Medicine 2016; 27:23

[20] Timashev P, Kuznetsova D, Koroleva A, Prodanets $N$, Deiwick A, Piskun Y, Bardakova K, Dzhoyashivili N, Kostjuk $S$, Zagaynova E, Rochev Y, Chichkov B, Bagratashvili V. Novel biodegradable star shaped polylactide scaffolds for bone regeneration fabricated by two-photon polymerization. Nanomedicine 2016; 11(9):1041-1053

[21] Domalik-Pyzik P, Morawska-Chochół A, Chłopek J, Rajzer I, Wrona A, Menaszek E, Ambroziak M. Polylactide/ polycaprolactone asymmetric membranes for guided bone regeneration. e-Polymers 2016; 16(5):351-358

[22] McDermott AM, Mason DE, Lin ASP, Guldberg RE, Boerckel JD. Influence of structural load-bearing scaffolds on mechanical load- and BMP-2-mediated bone regeneration. Journal of the Mechanical Behavior of Biomedical Materials 2016; 62:169-181
[23] Gredes T, Kunath F, Gedrange T, Kunert-Keil Ch. Bone Regeneration after Treatment with Covering Materials Composed of Flax Fibers and Biodegradable Plastics: $A$ Histological Study in Rats. BioMed Research International 2016; Article ID 5146285

[24] Zhaoqun D, Yun XWY. Characterization of structure and properties of polylactic fiber; Journal of Applied Polymer Science, Special Issue: Biopolymers and Renewably Sourced Polymers 2012; 125(S2): E149-E157.

[25] Cicero JA, Dorgan JR. Physical Properties and Fiber Morphology of Poly(lactic acid) Obtained from Continuous Two-Step Melt Spinning. Journal of Polymers and the Environment 2001; 9(1): 1-10

[26] Paakinahoa K, Elläa V, Syrjäläb S, Kellomäkia M. Melt spinning of poly(I/d)lactide 96/4: Effects of molecular weight and melt processing on hydrolytic degradation. Polymer Degradation and Stability 2009; 94(3):438-442.

[27] Schmack G, Tändler B, Optiz G, Vogel R, Komber $H$, Häußler L, Voigt D, Weinmann S, Heinemann M, Fritz H-G. High-speed melt spinning of various grades of polylactides. Journal of Applied Polymer Science 2004; 91(2): 800-806.

[28] Krucińska I, Boguń M, Chrzanowska O, Chrzanowski $M$, Król P. Research concerning fabrication of fibrous osteoconductive PLGA/HApnanocomposite material using the method of electrospinning from polymer solution. Autex Research Journal 2013; 13(3):57-66.

[29] Signori F, Coltelli M-B, Bronco S. Thermal degradation of poly(lactic acid)(PLA) and poly(butylene adipateco-terephthalate)(PBAT) and their blends upon melt processing. Polymer Degradation and Stability 2009; 94:74-82

[30] Król P, Boguń M, Szparaga G, Mikołajczyk T. Poly(L-DLLactic Acid) (PLDLA) and Poly(Lactic Acid-co-Glycolide) (PGLA) in Wet Spinning Technology of Fibers Forming. Proceedings of International Conference on Medical Textiles and Healthcare Products, MedTex2015, Lodz, Poland 2015

[31] Boguń M, Szparaga G, Król P, Mikołajczyk T, Rabiej S. Calcium Alginate Fibers Containing Metallic Nanoadditives. Journal of Applied Polymer Science 2014; 131(9):40223.

[32] Boguń M, Rabiej S. The Influence of Fiber Formation Conditions on the Structureand Properties of Nanocomposite Alginate Fibers Containing Tricalcium Phosphateor Montmorillonite. Polymer Composites 2010;31:1321-1331.

[33] Gervaso F,Padmanabhan SK,Scalera F,Sannino A, Licciulli A. Mechanical stability of highly porous hydroxyapatite scaffolds during different stages of in vitro studies. Materials Letters 2016; 185:239-242.

[34] Khojasteh A,Fahimipour F,Eslaminejad MB, Jafarian $M$, Jahangir S,Bastami F, Tahriri M,Karkhaneh A, Tayebi $L$. Development of PLGA-coated $\beta$-TCP scaffolds containing VEGF for bone tissue engineering. Materials Science and Engineering 2016;69: 780-788.

[35] Qi H,Ye Z,Ren H,Chen N,Zeng Q,Wu X,Lu T. Bioactivity assessment of PLLA/PCL/HAP electrospunnanofibrous scaffolds for bone tissue engineering.Life Sciences 2016;148:139-144.

[36] Ma R, Yu Z, Tang S, Pan Y, Wei J, Tang T. Osseointegration of nanohydroxyapatite- or nano-calcium silicateincorporated polyetheretherketonebioactive composite in vivo. International Journal of Nanomedicine 2016;11:60236033 
[37] Khoshakhlagh P,Rabiee SM,Kiaee G,Heidari P,Miri AK,Moradi R,Moztarzadeh F,Ravarian R. Development and characterization of a bioglass/chitosan composite as an injectable bone substitute. Carbohydrate Polymers 2017; 157:1261-1271

[38] PremAnanth K,Joseph Nathanael A,Jose SP,Oh $T H$, Mangalaraj $D$. A novel silica nanotube reinforced ionic incorporated hydroxyapatite composite coating on polypyrrole coated 316L SS for implant application. Materials Science and Engineering C 2016;59:1110-1124

[39] Zhao X,You J,Xie Y,Cao H,Liu X. Nanoporous SiO2/TiO2 composite coating for orthopedic application. Materials Letters 2015;152:53-56

[40] Choi AH,Ben-Nissan B.Calcium phosphate nanocoatings and nanocomposites, part I: Recent developments and advancements in tissue engineering and bioimaging. Nanomedicine 2015; 10(14):2249-2261

[41] Boguń M, Krucińska I, Król P, Szparaga G, Mikołajczyk T, Dobrzyński $P$, Kowalczuk M,Kasperczak J, Pastusiak M, Smola A. Sposóbwytwarzaniawłókien o rozmiarachmikrometrycznych i podwyższonychwłaściw ościachwytrzymałościowych z poli(kwasumlekowego) orazjegokopolimerówmetodą $\mathrm{z}$ roztworunamokro.Patent PL 399819 (2014).

[42] Ziabicki A. Fundamentals of fibre formation: The Science of Fibre Spinning and Drawing. John Wiley\&Sons, USA, 1976 ,

[43] Mikołajczyk T, Boguń M, Rabiej S, Król P. Zinc Alginate Fibres Containing Nanosilica", Fibres\&Textiles in Eastern Europe 2010; 6:39.
[44] Rabiej M. Application of the genetic algorithms and multiobjective optimisation to the resolution ofX-Ray diffraction curves of semicrystalline polymers. Fibres Text. East. Eur. 2003;11:83-87.

[45] Rabiej M, Application of multicriterial optimization of crystallinity degree of semicrystalline polymers. Polimery 2003;48:288-295.

[46] Stoclet G, Seguela R, Lefebvre J-M and Rochas C.New insights on the strain-induced mesophase of poly $(D, L-$ lactide): in situ WAXS and DSC study of the thermomechanical stability. Macromolecules 2010, 43: 72287237.

[47] Solarski S, Ferreira $M$ and Devaux E. Characterization of the thermal properties of PLA fibers by modulated differential scanning calorimetry Polymer 2005, 46: 1118711192.

[48] Puchalski M, Sulak K, Chrzanowski M, Sztajnowski S, Krucińska I. Effect of processing variables on the thermal and physical properties of poly(L-lactide) spun bond fabrics. Textile Research Journal 2015, 85: 535-547.

[49] Puchalski M, Kwolek S., Szparaga G.,Chrzanowski M., Krucińska I.Investigation of the influence of PLA molecular structure on the crystalline forms ( $\alpha$ " and $\alpha$ ) and Mechanical Properties ofWet Spinning Fibres. Polymers, 2017, 9(1), 18 